\title{
P-Y Curves of Laterally Loaded Piles Near Earth Slopes
}

\author{
Soha Emad Said, Ayman Lotfy Fayed, Yasser El Mossallamy
}

\begin{abstract}
Design of piles under lateral loads using numerical analysis is a time-consuming process, requiring competent geotechnical engineers who can accurately model the soil profile and construction sequence. Therefore, most engineers have resorted to the p-y method that is a less time-consuming process in both the modeling and running time. Contrary to the numerical analysis method, the p-y method doesn't require the burden of constructing a complicated $3 D$ model. This method simply uses the relation between the soil resistance per unit length $(p)$ and the lateral deformation (y) to deduce the straining actions on the pile, bending moment, and shear forces, which govern the structural design. However, the simplicity of this method comes with its shortcomings. The p-y method, for instance, cannot directly take into account the effect of earth slopes on the laterally loaded piles, and its results are somewhat approximate.
\end{abstract}

A well-instrumented case study from the Caltrans site at Oregan State University is analyzed in this research. The studied case consists of a laterally loaded single vertical pile embedded in a cohesive soil layer near an earth slope of $2 \mathrm{H}: 1 \mathrm{~V}$. A three dimensional numerical model of the case study is constructed, utilizing the finite element code, Plaxis 3D 2020. The p-y curves of the loaded piles were back-calculated from the numerical model using the elastic beam theory by performing the differentiation of the shear force acting on the pile along the full height of the earth slope. Normalized p-y curves were obtained to determine the p-multiplier, a factor that helps convert the $p$-y relation of a pile in leveled ground to that of a pile near earth slopes. Overall, it was found that the p-multiplier ranges between (0.4-0.8), (0.6-0.83), (0.8-0.95), and (0.98-1) for piles located at a distance of $0 D, 2 D$, $4 D$, and $8 D$ respectively from the crest of the earth slope, for various target depths. A parametric study for the effect of the distance of the pile from the crest of the slope, as well as the slope inclination, on the p-y curves was conducted. The curves were constructed for a single pile located at distances of $0 D, 2 D, 4 D$, and $8 D$ from the crest of the earth slope. The performed study revealed that the p-multiplier, at a target depth of $1 \mathrm{~m}$, measured from the top of the pile, for the studied slope inclinations, ranges between (0.3-0.45) for the pile at a distance of $0 D,(0.76-0.8)$ at a distance of 2D, (0.82-0.93) at a distance of $4 \mathrm{D}$ and (0.98-1) at a distance 8D. Analysis results showed that the effect of slope inclination diminishes when the pile is placed at a distance $8 D$ from the crest or farther. These values can be implemented into p-y curves software, such as LPILE, to determine the straining actions required for design of a laterally loaded pile near sloping ground.

Revised Manuscript Received on April 04, 2020.

* Correspondence Author

Soha Emad Said*, Department of Structural Engineering, Ain Shams University, Cairo, Egypt. Email: soha.emad@eng.asu.edu.eg

Ayman Lotfy Fayed, Department of Structural Engineering, Ain Shams University, Cairo, Egypt. Email: ayman_fayed@eng.asu.edu.eg

Yasser El Mossallamy, Department of Structural Engineering, Ain Shams University, Cairo, Egypt. Email: yasserelmossallamy@gmail.com

(c) The Authors. Published by Blue Eyes Intelligence Engineering and Sciences Publication (BEIESP). This is an open access article under the CC BY-NC-ND license (http://creativecommons.org/licenses/by-nc-nd/4.0/)
Keywords: Earth Slopes, Finite Element Modelling, Lateral Loads, Piles, P-y Curves

\section{INTRODUCTION}

\section{The analysis of laterally loaded piles (pile-soil}

interaction) requires a nonlinear approach to accurately model the soil behaviour. In previous years, the main strategies used were either based upon the elasticity theory [1] or the modulus of subgrade reaction theory [2], which are purely linear methods. The p-y curves method provides a simple technique to model the non-linearity of the pile-soil relation. P-y curves can be back-calculated and constructed by either full-scale lateral load tests, centrifuge tests or numerical analysis models. Based on full-scale lateral tests on piles in sandy soils [3], a family of p-y curves was obtained using sand and pile properties. In order to establish the p-y curves for soft clay under static loading [4], four full-scale lateral load tests were performed on a steel pipe pile embedded in soft clay. Reese et al.[5], performed two static lateral load tests on a $2 \mathrm{ft}$ diameter steel pipe pile embedded in stiff, overconsolidated clay under the water table to establish the p-y curves for stiff clay below the water table. At present, most of the available research and design recommendations are only available for piles in leveled ground. Several researchers investigated the effect of earth slope on the lateral capacity of piles using small-scale model tests, centrifuge tests, and full-scale tests. Mezazigh and Levacher [6] conducted 59 centrifuge tests on a single aluminum model pile to study the effect of the proximity of the pile from the earth slope on the pile lateral response, aiming to determine a coefficient that can be applied to p-y curves for leveled ground to validate the existing curves for piles near slope simply by multiplying the values by a specific factor. A finite element analysis [7] was performed to study the effect of slope inclination on the lateral response and behaviour of the pile. Chae et al. [8] conducted small scale tests accompanied by finite element analysis to construct p-y curves and determine the p-multiplier. Three full-scale tests [9] on steel pipe piles were carried out to study the effect of earth slopes on the lateral response of piles. Georgiadis and Georgiadis [10] carried out a finite element analysis using Plaxis 3-D software to study the behaviour of piles near the crest of an earth slope under undrained loading conditions for cohesive soil.

Published By:

Blue Eyes Intelligence Engineering \& Sciences Publication

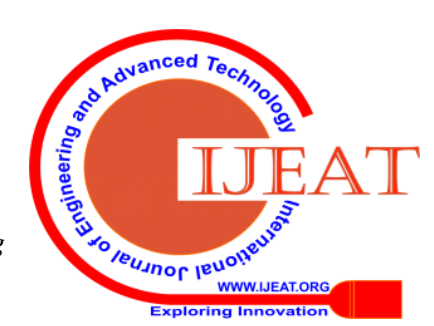


Four different slope angles were used in the analysis; 0, 20, 30 , and 40 degrees. Based on the findings, new p-y criterion for static loading of piles in clay were proposed.Nimityongskul et al. [11] performed seven full-scale tests in Oregan State University to study the effect of the proximity of the slope on the lateral response of the pile as well as construct the p-y curves. Verhoef [12] performed a parametric study using numerical modeling software on a homogeneous sand layer, and interbedded layers of clay and sand with slope angles 1:3 and 1:4 on a single laterally loaded pile. From the p-y curves, it was observed that the lateral capacity of the pile is more affected by the slope for the case of sand than that for clay. Sawant [13] also performed a parametric study for a single pile embedded in clay located at the crest, to study the effect of length to diameter ratio, slope inclination angle, undrained cohesion, and lateral load on the pile response. Finite element modelling accompanied by finite difference technique [14] was used in backcalculating the p-y curves for monopiles in clay. Yang et al. [15], modified the passive wedge model and available p-y charts, introducing the weakening effect of the soil resistance for the case of a laterally loaded pile near earth slope.This paper aims to deduce back-calculated p-y curves from numerical model analysis as well as determine the p-multiplier.

\section{CASE STUDY}

\section{A. Site Description}

The case study was reported by Nimityongskul, et al. [11]. The tests were conducted near the western edge of the Oregan State University (OSU) campus, located within the Geotechnical Engineering Field Research Site (GEFRS), a popular site where multiple previous tests have been conducted ever since 1972, also referred to as the Caltrans site. The top layer is referred to as upper cohesive layer (UC) extending to a depth of $3 \mathrm{~m}$ below the ground surface. The UC layer is underlain by a poorly graded sand layer, upper sand layer (US), of depth $1 \mathrm{~m}$. Below the US layer is a medium-stiff clay layer, lower cohesive layer (LC), of thickness $1.5 \mathrm{~m}$, followed by a medium dense well-graded sand layer, lower sand (LS), of thickness $7 \mathrm{~m}$. Finally, the LS layer is underlain by a blue-grey clay layer (BGC) extending to approximately $-23 \mathrm{~m}$ from the ground surface. Since the top layer has a thickness of $10 \mathrm{D}$, the approved distance from previous literature in which the soil properties of the layer govern the lateral response of piles, the tests are considered in cohesive soil.

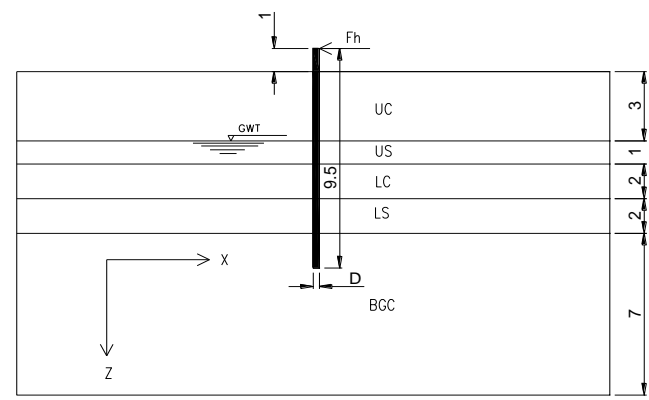

Fig. 1. shows the soil stratification at the Caltrans site.

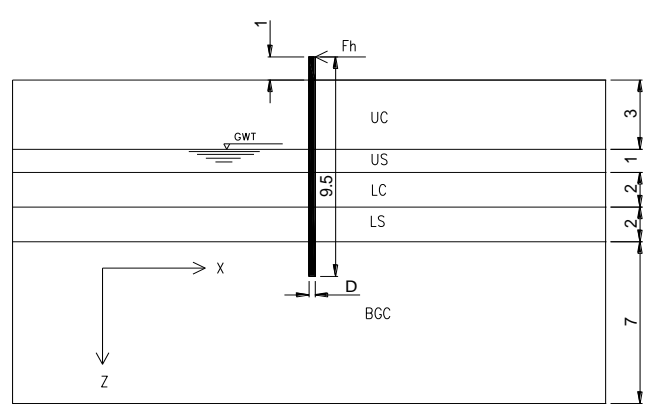

Fig. 1. Soil Stratification at Caltrans Site (all dimensions are in meters)

\section{B. Test Setup}

The piles used in the field test were hollow steel pipe piles with an outer diameter of $0.3238 \mathrm{~m}$ and a wall thickness of $0.0095 \mathrm{~m}$. The total length of the pile was $9.5 \mathrm{~m}$ with an embedment depth of $8.5 \mathrm{~m}$. Strain gauges were installed along the pile to measure the deformation, protected by two steel channels C 3X4.1 attached on opposite sides of the pile, to prevent damage during pile driving. Several lateral load tests were included in the test program; two tests in horizontal ground to provide the backbone load-displacement curve, and at distances 0D, 2D, 4D, and 8D from the crest of a $2 \mathrm{H}: 1 \mathrm{~V}$ slope where " $\mathrm{D}$ " is the pile diameter. The original terrain of the Caltrans site was relatively flat horizontal ground. To determine the lateral response of piles near earth slopes, a $2 \mathrm{H}: 1 \mathrm{~V}$ slope was constructed after the completion of the lateral load tests in horizontal ground. The test piles were loaded step by step by a hydraulic actuator, shown in Fig. 2, to construct the load-displacement curves, hence requiring reaction piles to provide reactions for the test piles. The loading protocol for each step was for the pile to be loaded until a target displacement was reached and maintained for about 5 to 10 minutes to ensure the stabilization of the pile. Afterward, the procedure was repeated and the next displacement increment was applied and so forth until the maximum load capacity of the test piles was reached. Various instruments were used to register the output of the lateral load tests, including strain gauges, tiltmeters, load cells, and linear potentiometers.

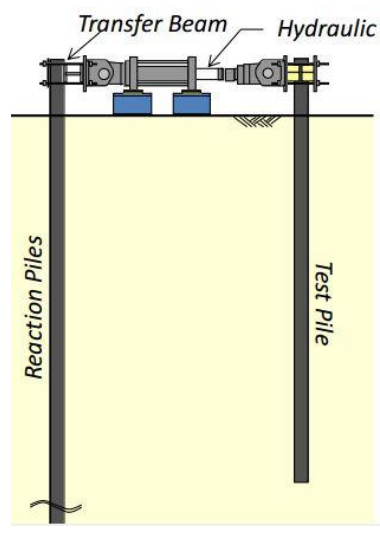

Fig. 2. Field Pile Load Tests

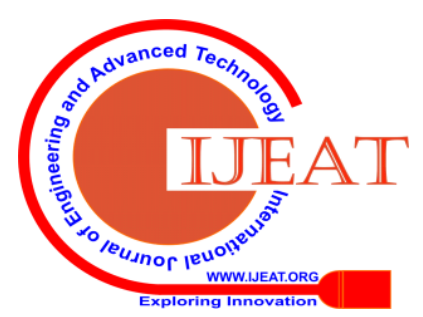




\section{METHODOLOGY}

\section{A. Soil Constitutive Model}

The main behaviour that concerns geotechnical engineers regarding piles is the deformation. For that reason, the main target upon verification was to find the best constitutive model to simulate the soil-pile interaction system and compare the load vs. deformation curves from the field measurements to the numerical analysis model. The hardening soil model was implemented using Plaxis 3D 2020 software to construct the numerical model, which provides a more precise solution as it introduces the effect of confining stress with depth. The soil parameters used to model the stratification in the case study for the hardening model were deduced from the field test data; SPT, CPT, etc.... Table- I shows the HM soil parameters used to construct the numerical model.

Table- I Adapted Soil Parameters in Numerical Model

\begin{tabular}{|c|c|c|c|c|c|}
\hline & UC & US & LC & 15 & BGC \\
\hline Condition & drained & drained & undra ined & drained & undra ined \\
\hline$\gamma_{1}\left(\mathrm{kN} / \mathrm{m}^{3}\right)$ & 18.1 & 20.4 & 18.1 & 20.4 & 17.3 \\
\hline$\gamma_{\text {sat }}\left(\mathrm{kN} / \mathrm{m}^{3}\right)$ & 18.3 & 22 & 18.3 & 22 & 17.5 \\
\hline$E_{\text {go }}(\mathrm{kPa})$ & 7565 & 28730 & 7565 & 28730 & 7565 \\
\hline $\mathrm{E}_{\mathrm{u}}(\mathrm{kPa})$ & 22700 & 86190 & 22700 & 86190 & 22700 \\
\hline $\mathrm{c}_{\text {sf }}(\mathrm{kPa})$ & 115 & 0 & 115 & 0 & 168 \\
\hline (1) & 0 & 45 & 0 & 40 & 0 \\
\hline$\Psi$ & 0 & 5 & 0 & 5 & 0 \\
\hline$k_{0}$ & 0.56 & 0.307 & 0.97 & 0.3572 & 0.97 \\
\hline
\end{tabular}

\section{B. Pile Modelling}

The pile was modeled as a composite cylindrical volume element (diameter $=1 \mathrm{ft}=0.3048 \mathrm{~m}$ ) with EI equivalent to simulate the original EI parameters for the real tested pile. Table-II shows the pile parameters used for verification.

Table- II Pile Parameters

\begin{tabular}{|c|c|}
\hline Model & Linear Elastic \\
\hline $\mathbf{~} \mathbf{( k N / \mathbf { m } ^ { \mathbf { 3 } } )}$ & 78.5 \\
\hline $\mathbf{E}_{\mathbf{e q}} \mathbf{( \mathbf { P a } )}$ & 57930000 \\
\hline $\mathbf{v}$ & 0.27 \\
\hline
\end{tabular}

\section{Greometry of the 3D Model}

The cross-section for the analyzed case is shown in Fig.3. It is to be noted that the model was extended out of plan a distance $42 \mathrm{D}=14 \mathrm{~m}$. The model dimensions were chosen large enough to minimize the effect of boundary conditions on the stress and strain fields. Fig. 4. shows the three-dimensional numerical analysis model overview.

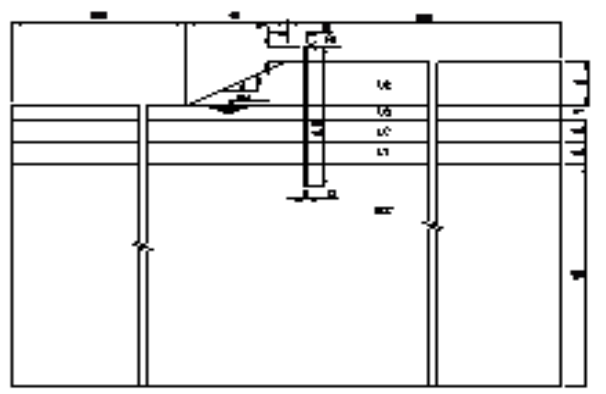

Fig. 3. Finite Element Model Cross-Section

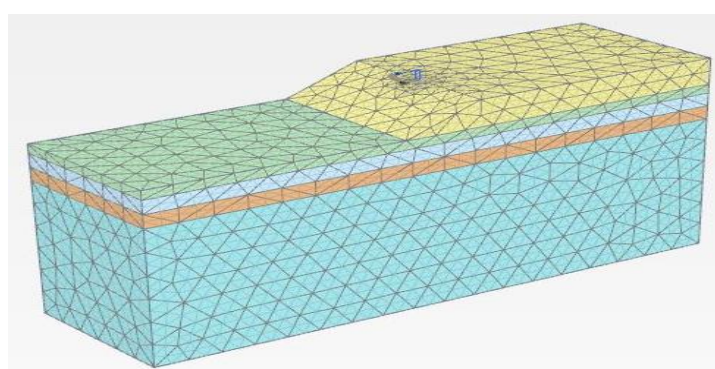

Fig. 4. Overview and Generated Mesh of the Numerical Model

\section{Verification}

Field test results were available for the case of a single vertical pile located at distances of $0 \mathrm{D}, 2 \mathrm{D}, 4 \mathrm{D}$, and $8 \mathrm{D}$ from the crest of a $2 \mathrm{H}: 1 \mathrm{~V}$ slope. From the available data and measured load-deformation behavior, validation of the numerical model was performed by comparing the load-deformation curves from analysis with the measured curves. Furthermore, to provide the reference curve, also known as the backbone curve, the leveled ground condition was also studied in the field and numerical model to ensure the validity of numerical modeling in detecting the soil behaviour under different conditions. Fig. 5. (a), (b), (c), and (d) show the relation between the measured and predicted load-deformation behviour in sloping ground at different distances from the crest. Whereas Fig. 5.(e) shows the relation between the measured and predicted load-deformation behviour for leveled ground.

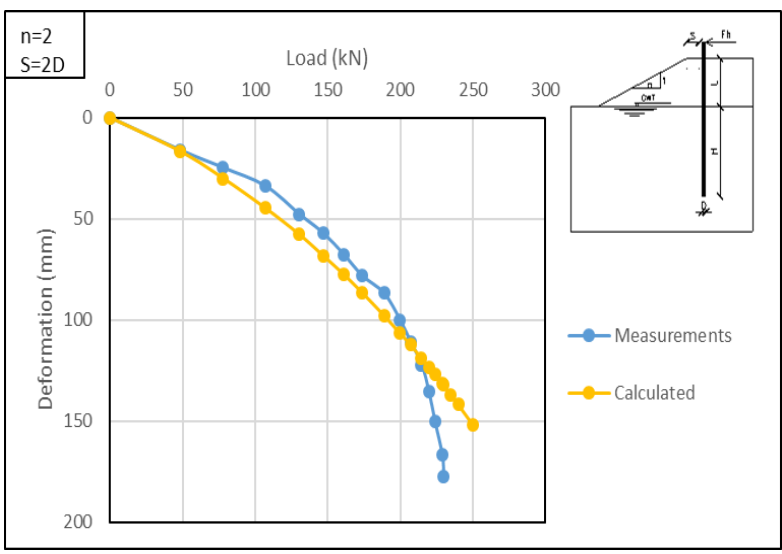

(a)

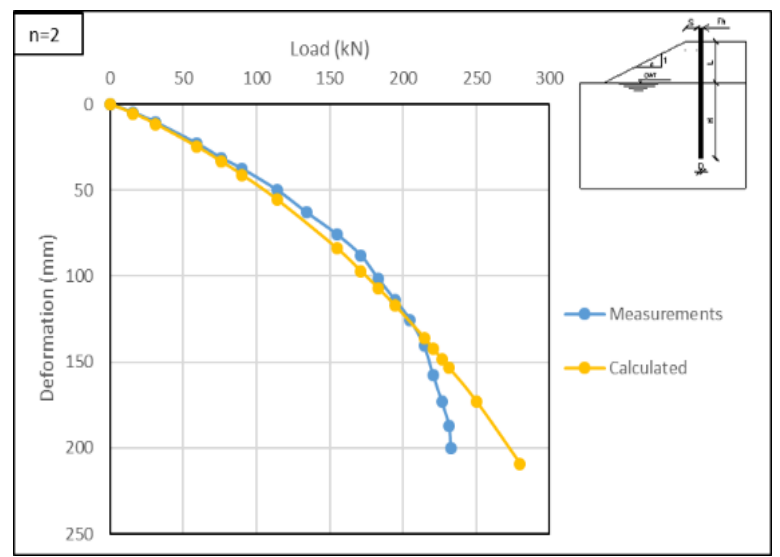

(b)

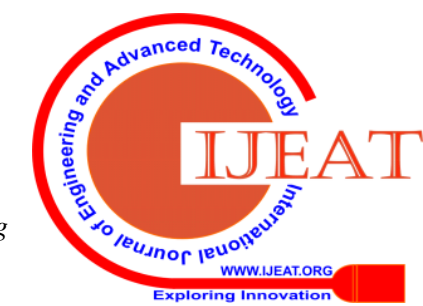




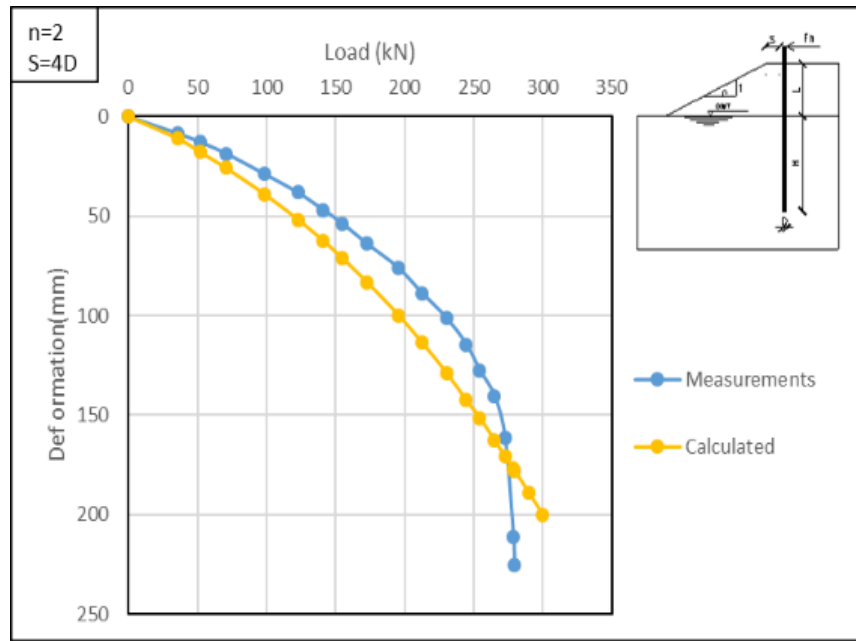

(c)

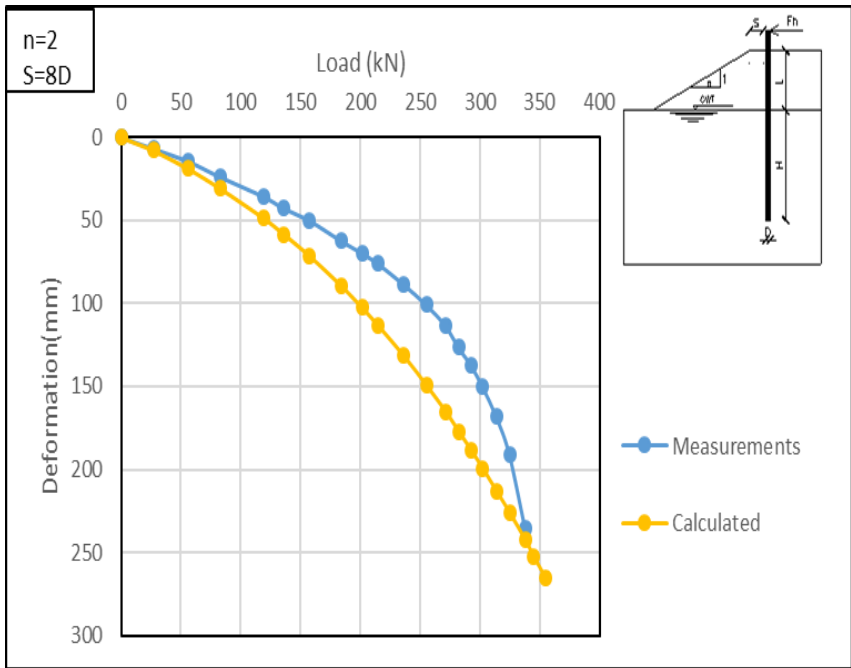

(d)

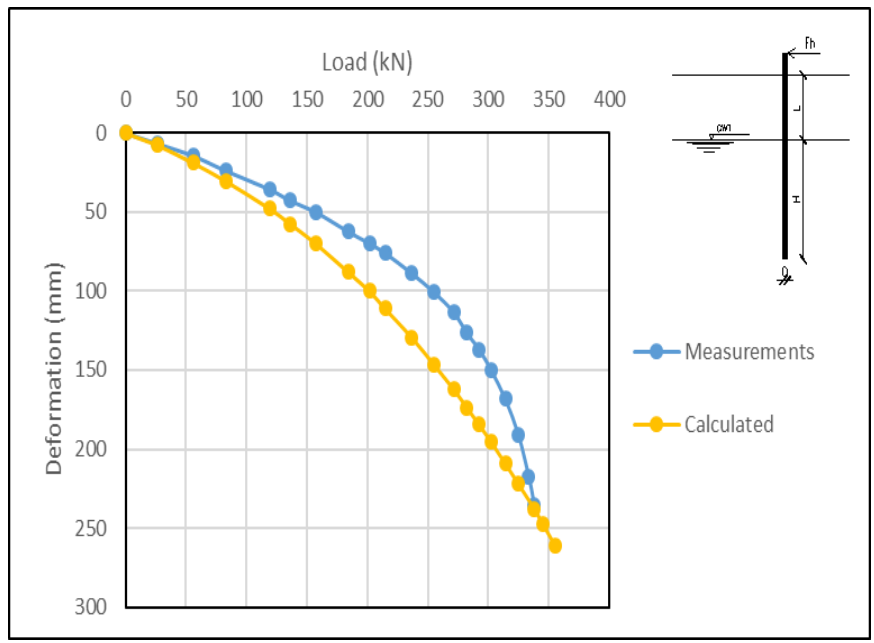

(e)

Fig. 5. Comparison Between Measured and Calculated

Load Vs. Deformation Curve for a Single Pile at

Distances a)0D b)2D c)4D d)8D e)Levelled Ground

In order to quantify the degree of accuracy of the numerical model in predicting the measured load-deformation behavior, a statistical analysis was performed to define the percentage of error in each case, shown in

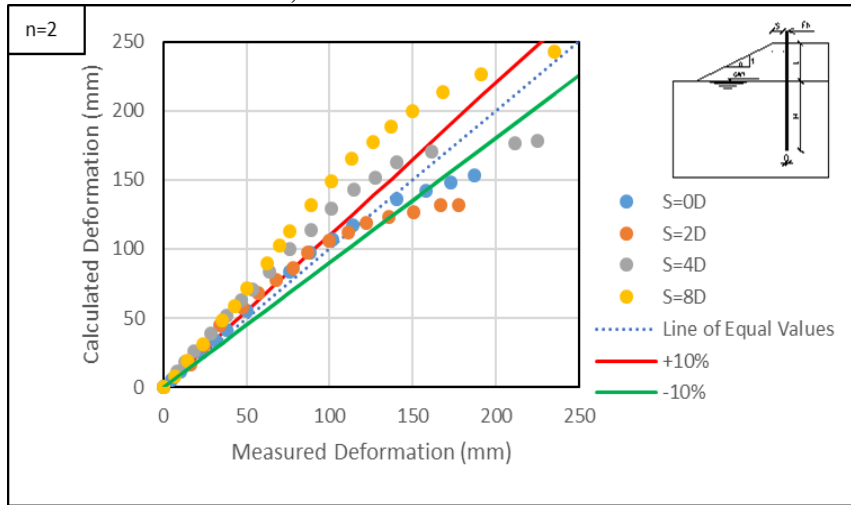

Fig. 6.

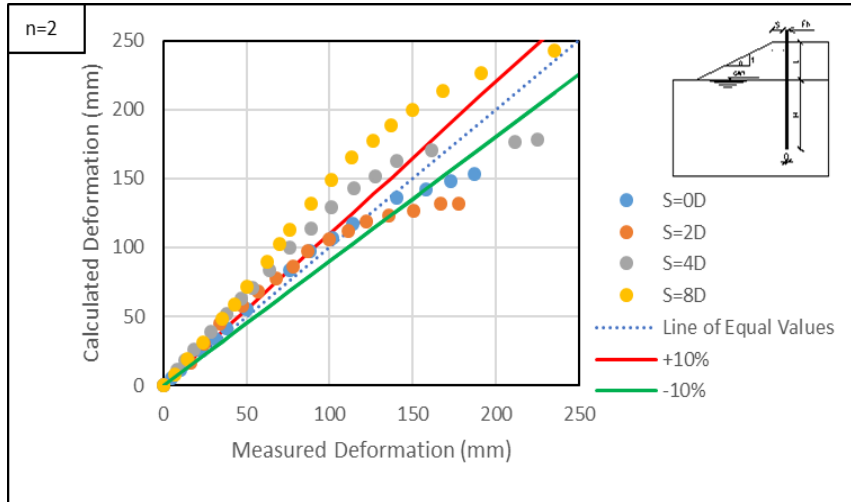

Fig. 6. Measured Vs. Calculated Deformation

IV. P-Y CURVES DEDUCTION FROM NUMERICAL MODEL

\section{A. Method for Backcalculating p-y Curves}

The construction of p-y curves from numerical analysis results is often referred to as back calculating. This terminology is due to the fact that existing p-y curves are used to design laterally loaded piles by deducing the straining actions on the pile required to design. Upon constructing p-y curves from analysis data, the straining actions are already available and the required target is to generate the p-y curves, hence the term back-calculated.

In this paper, the elastic beam method was used to generate the back-calculated p-y curves using (1), (2), (3), (4), and (5). The bending moments, shear forces and associated soil displacements at each load step for depth intervals of 0.5 meters starting from the ground surface measured from the top of the pile were obtained and displayed in a spreadsheet. Then, the finite difference method was used to differentiate the shear force at each load step for each target depth to obtain the corresponding soil reaction, $\mathrm{p}$.

$$
\begin{aligned}
& \frac{d M}{d x}+N \frac{d y}{d x}-V=0 \\
& \frac{d^{2} M}{d x^{2}}+N \frac{d^{2} y}{d x^{2}}-\frac{d V}{d x}=0
\end{aligned}
$$

In absence of axial force on the pile :

$\frac{d V}{d x}=\frac{d^{2} M}{d z^{2}}=\frac{E I d^{4} y}{d x^{2}}$

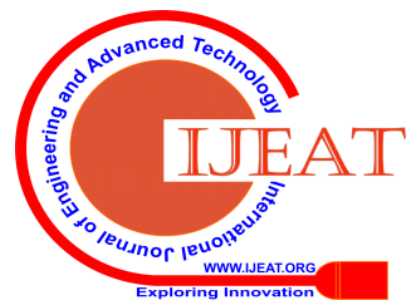


From the following identities, the soil resistance per unit length can be defined:

$$
\begin{aligned}
& \mathrm{V}=\frac{\mathrm{dM}}{\mathrm{dz}} \\
& \mathrm{p}=\frac{\mathrm{dV}}{\mathrm{dz}}
\end{aligned}
$$

where,

$\mathrm{E}=$ Modulus of elasticity $\left(\mathrm{kN} / \mathrm{m}^{2}\right)$

$\mathrm{I}=$ Moment of inertia $\left(\mathrm{m}^{4}\right)$

$\mathrm{P}=$ Axial force on the pile $(\mathrm{kN})$

$\mathrm{M}=$ Moment on the pile (kN.m)

$\mathrm{V}=$ Shear force on the pile $(\mathrm{kN})$

$\mathrm{z}=$ Depth along length of the pile $(\mathrm{m})$

$\mathrm{p}=$ Soil resistance per unit length $(\mathrm{kN} / \mathrm{m})$

Fig. 7. shows the back-calculated p-y curves from numerical model analysis for a pile placed at distances $0 \mathrm{D}, 2 \mathrm{D}, 4 \mathrm{D}$, and $8 \mathrm{D}$, respectively from the crest of a $2 \mathrm{H}: 1 \mathrm{~V}$ slope at target depths $1,1.5,2,2.5$, 3m measured from the top of the pile. It is noted from the figure that the soil resistance increases with depth.

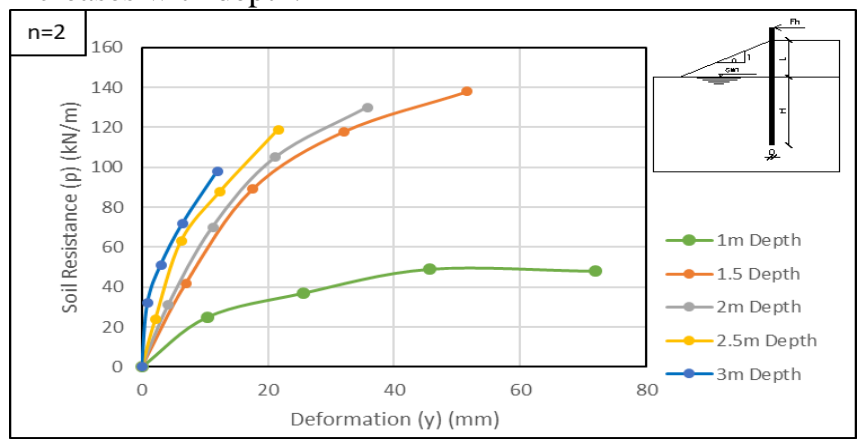

(a)

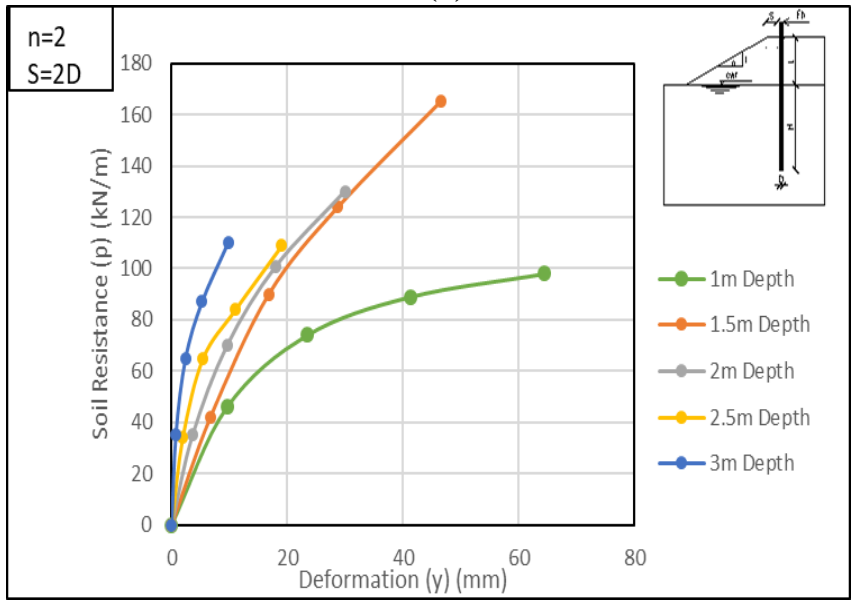

(b)

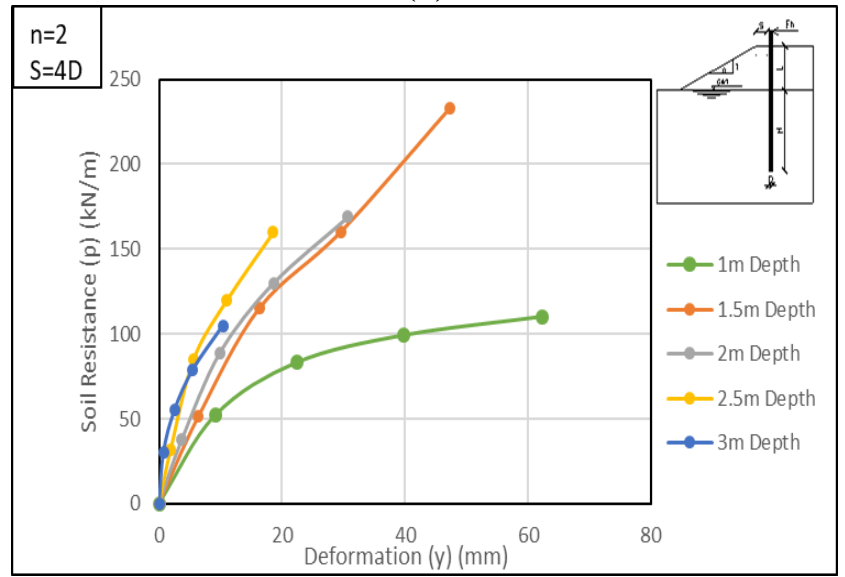

Retrieval Number: D7763049420/2020@BEIESP (c)

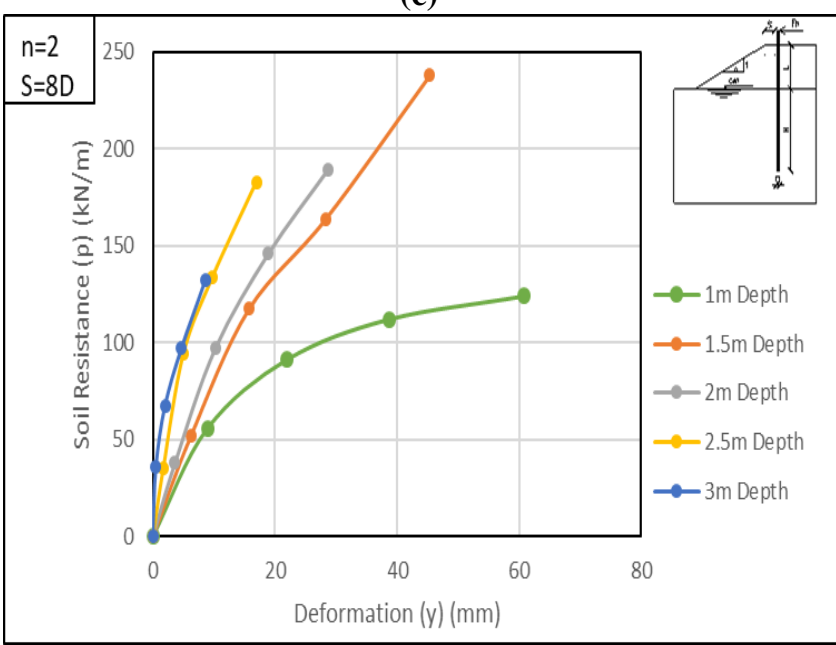

(d)

Fig. 7. Back calculated p-y Curves from Numerical Analysis for Pile at Distances a)0D b)2D c)4D d)8D

A statistical analysis, shown in Fig. 8. was performed to validate the method of using finite difference to construct p-y curves by comparing the soil resistance obtained from field test data to that from the numerical model at specified lateral deformations.

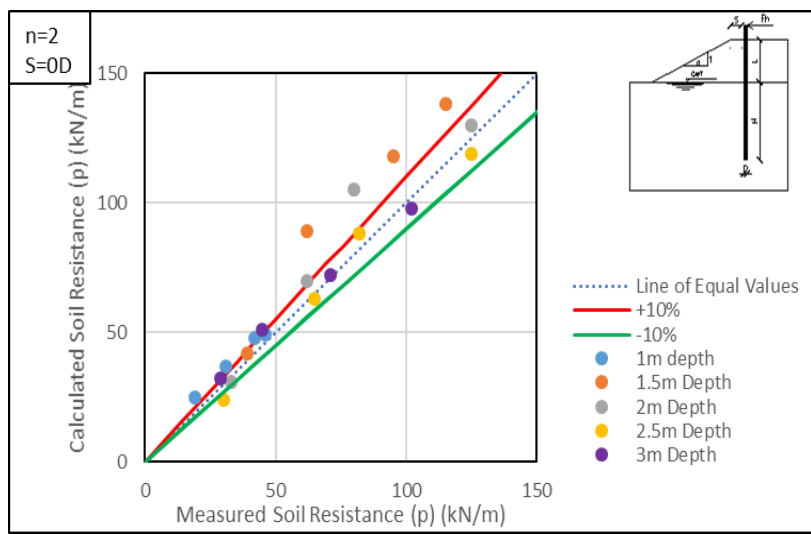

(a)

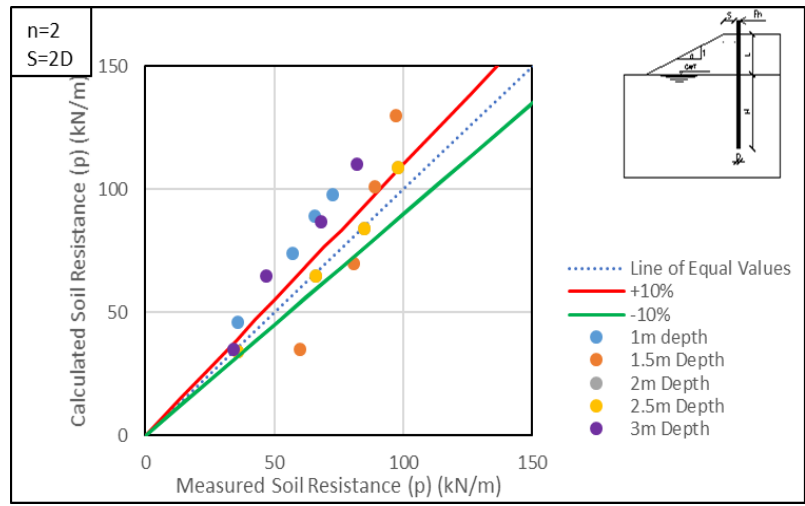

(b) 


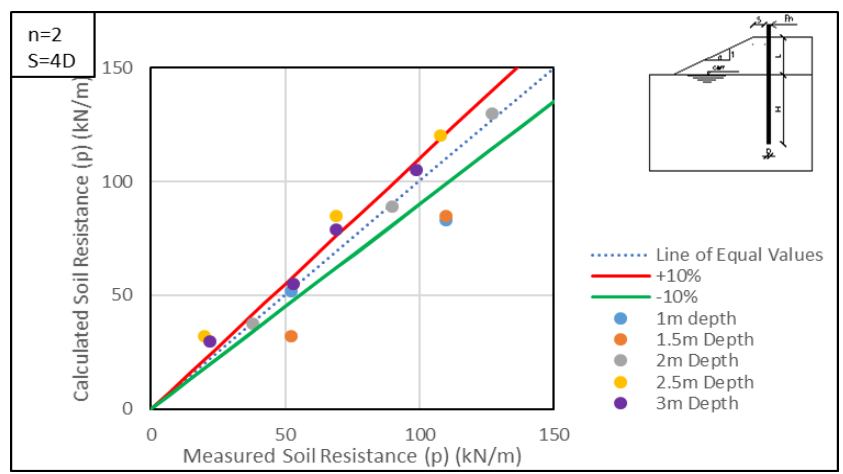

(c)

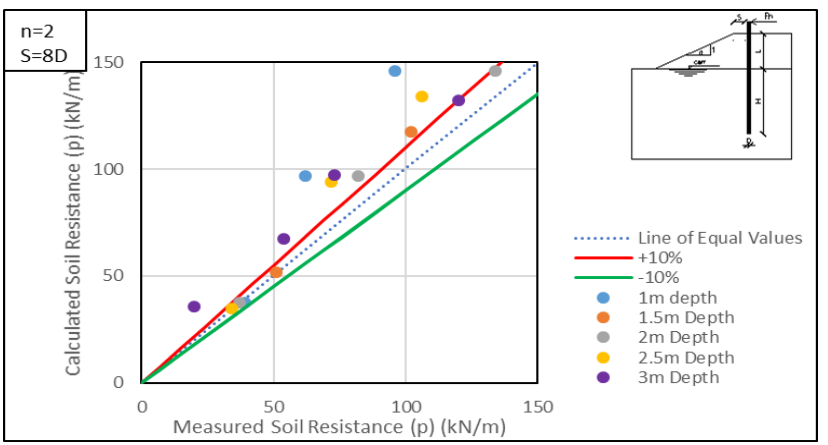

(d)

Fig. 8. Comparison Between Backcalculated p-y Curves from Field Measurements and Numerical Model Analysis for Pile at Distances a)0D b)2D c)4D d)8D

\section{B. Normlized p-y Curves}

Most p-y curves softwares cannot take into account the effect of sloping grounds on the lateral pile capacity. Since the goal of using p-y curves is to assist in the design of laterally loaded piles, the graphical representation of the soil reaction per unit length versus lateral pile deflection isn't tangible for geotechnical engineers. Hence the need for factors to account for the sloping effect to be implemented in the $p-y$ software programs. These factors are commonly known as p-multipliers. The p-multipliers are factors obtained from the normalization of the previously constructed p-y curves with the backbone curve for pile in leveled ground. The normalized p-y curves from numerical model analysis for a pile at distances of $0 \mathrm{D}, 2 \mathrm{D}, 4 \mathrm{D}$, and $8 \mathrm{D}$ from the crest of a 2:1 slope are shown in Fig. 9. respectively for target depths at $0.5 \mathrm{~m}$ intervals measured from the top of the pile starting at the ground surface. The vertical axis represents the $\mathrm{p}$-multiplier $\left(\mathrm{p}_{\text {slope }} / \mathrm{p}_{\mathrm{hz}}\right.$ ), while the horizontal axis represents the associated deformation of the pile in mms

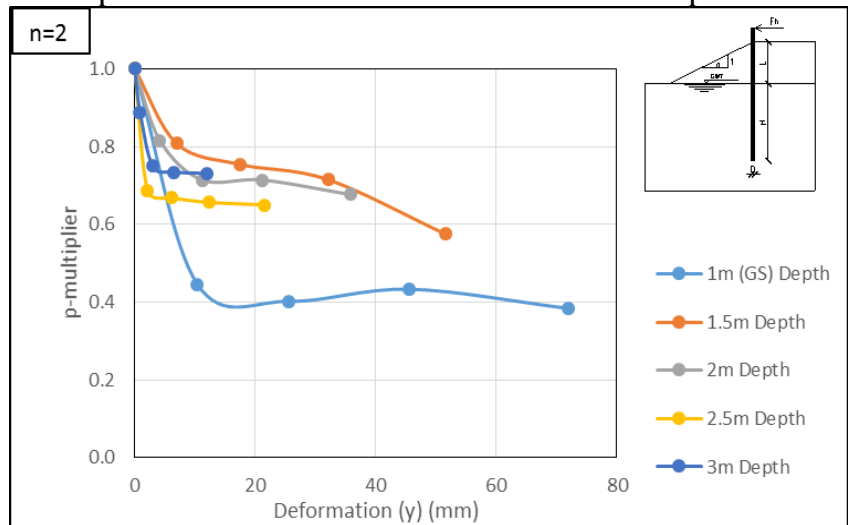

(a)

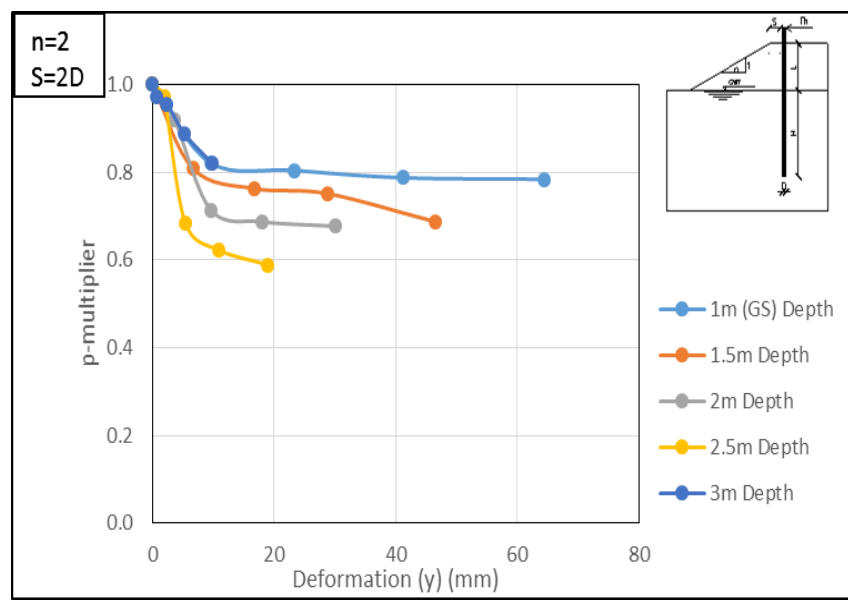

(b)

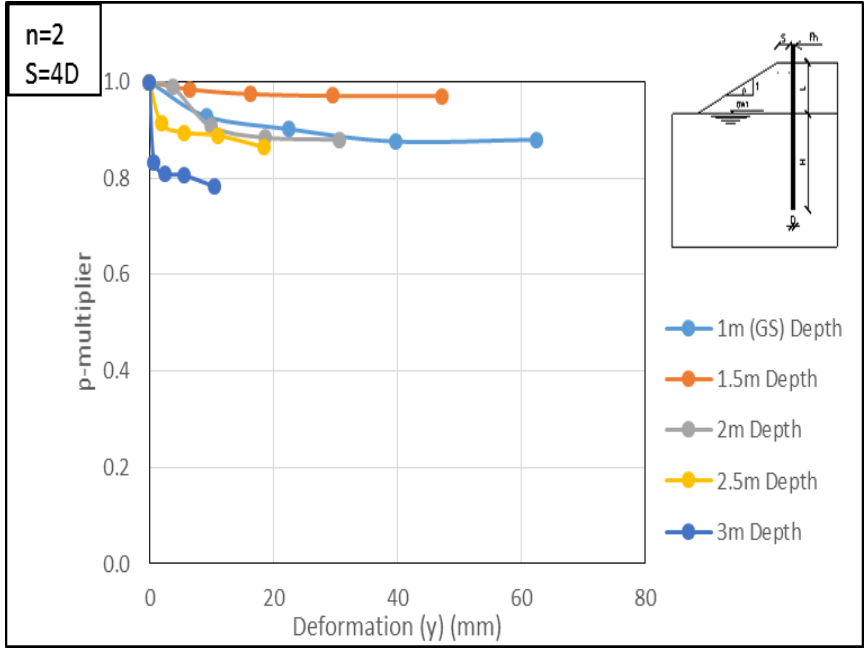

(c)

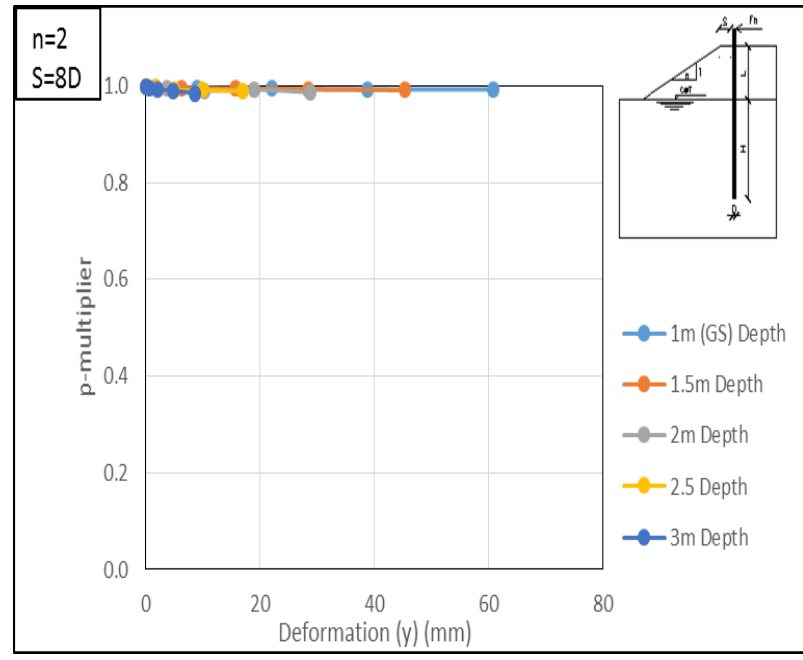

(d)

Fig. 9. Normalized p-y curves from Numerical Model Analysis for a Pile at Distances; a)0D b)2D c)4D d)8D from Crest of 2:1 Slope

\section{RESULTS AND DISCUSSION}

A. Interpretation of the Verified Model Using Statistics From Fig. and 


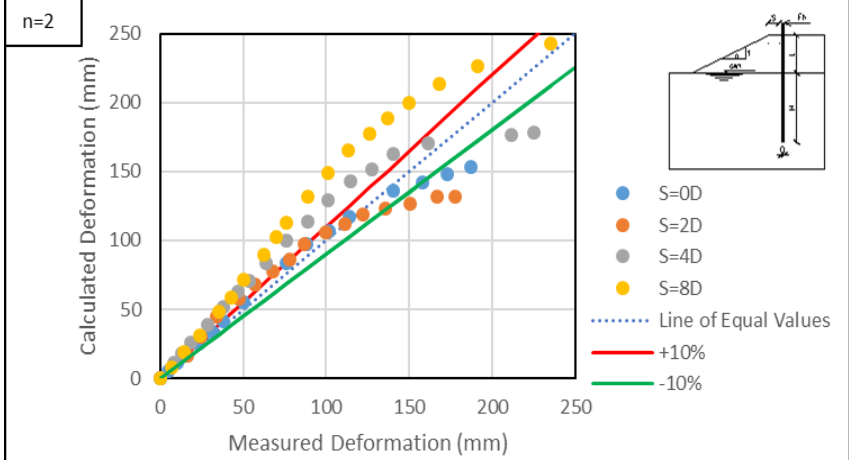

Fig. 6., in section III, several observations can be made. For the pile at the crest, distance $0 \mathrm{D}$, most applied loads are within $\pm 10 \%$ error range. However, for loads greater than $220 \mathrm{kN}$, the percentage of error slightly increases until it reaches $18 \%$. At a distance of $2 \mathrm{D}$ from the crest, for small applied loads, less than $50 \mathrm{kN}$, the average error is $4 \%$. For loads ranging between $50 \mathrm{kN}$ and $160 \mathrm{kN}$, the error slightly increases with an average value of $20 \%$ until the percentage of error gradually returns to the $\pm 10 \%$ error range up to a load application of $220 \mathrm{kN}$. As the load exceeds $220 \mathrm{kN}$, the error increases slightly with an average value of $26 \%$. That is due to the nonlinearity of the steel pile material, which wasn't taken into account in the model. At a distance of $4 \mathrm{D}$, for loads less than $140 \mathrm{kN}$, the measured and calculated deformation are relatively close. However, for loads higher than $140 \mathrm{kN}$, the percentage of error increases until it reaches an average of $25 \%$. As the pile is placed farther from the crest, at a distance of $8 \mathrm{D}$, for loads less than $135 \mathrm{kN}$, the measured and calculated deformations coincide with the line of equal values (error tends to zero), but for loads higher than $135 \mathrm{kN}$, the error increases to an average of $30 \%$.

Overall, the numerical model results compare exceptionally well with the field test results, with a coefficient of determination $\left(\mathrm{R}^{2}\right)$ of 0.9657 for $0 \mathrm{D}, 0.878$ for $2 \mathrm{D}, 0.867$ for $4 \mathrm{D}$, and 0.95 for $8 \mathrm{D}$. can be noticed from Fig. (5) and table (III) that the ultimate capacity of the pile increases as the pile distance from the earth slope increases, accurately simulating the actual pile behaviour. When the pile is placed at a distance of $0 \mathrm{D}$, at the crest, the slope value (m) from the modified chin method is 0.003 , leading to an estimated ultimate capacity of $333.3 \mathrm{kN}$. At a distance of 2D from the crest, the slope value $(\mathrm{m})$ is 0.0029 , and the estimated ultimate capacity is $344.8 \mathrm{kN}$. As the pile is placed farther from the crest, at a distance of $4 \mathrm{D}$, the estimated ultimate capacity of the pile reaches $400 \mathrm{kN}$ for a slope value $(\mathrm{m})$ of 0.0025 . Finally, when the pile is placed at a distance of $8 \mathrm{D}$ from the crest, the slope value $(\mathrm{m})$ is 0.0021 resulting in an estimated ultimate capacity of $487.8 \mathrm{kN}$. By comparing both the slope (m) and $\mathrm{Q}_{\mathrm{ult}}$ values for the leveled ground case and $8 \mathrm{D}$ case, it is observed that the behaviour of the pile placed at a distance $8 \mathrm{D}$ from the earth slope approaches that of a pile placed in leveled ground, i.e., the effect of earth slope diminishes at a distance of 8D or farther.

\section{B. Interpretation of Backcalculated p-y Curves}

With reference to Section IV(A), from Fig. 7. and Fig. 8., for the case of the pile placed at the crest, $0 \mathrm{D}$, the percentage of error for the soil resistance is within the $\pm 10 \%$ limits for target depths, 1, 2.5, and 3m. For a target depth of $1.5 \mathrm{~m}$, the error is $9.8 \%$ for small soil resistance, less than $50 \mathrm{kN} / \mathrm{m}$. However, as the soil resistance increases, the error increases until it reaches an average value of 30\%. Also, for a target depth of $2 \mathrm{~m}$, the analysis results are in good agreement with the measured results, except for one point at a deformation of $21 \mathrm{~mm}$, where the error reaches $30 \%$. At $2 \mathrm{D}$, it is observed that the results for a target depth of $2.5 \mathrm{~m}$ show the best results, with all points within the $\pm 10 \%$ zone.

For small deformations, less than $10 \mathrm{~mm}$, for all target depths, the error is relatively low. As the deformation values increase, the error between the measured and calculated soil resistance increases. At 4D, for target depths 2 and 3m, the error is within $\pm 10 \%$. For a target depth of $1 \mathrm{~m}$, for deformations up to $20 \mathrm{~mm}$, the error is relatively large, with an average of $28 \%$. However, for deformations larger than $20 \mathrm{~mm}$, the error is only $11 \%$. As the pile is placed farther from the crest, at $8 \mathrm{D}$, the error slightly increases compared to the $4 \mathrm{D}$ case, yet still the values correspond well with the measured case. The comparison shows excellent agreement and validates the use of the finite difference method to construct p-y curves from numerical analysis models.

\section{Interpretation of Normalized p-y Curves}

It can be noticed from Fig. 9. , section $\operatorname{IV}(B)$, that the value of the p-multiplier, at a specified target depth, increases as the pile is placed farther from the crest of the slope until it tends to 1 when the pile is situated at a distance 8D; i.e., the effect of slope diminishes at a distance of $8 \mathrm{D}$ and the lateral behaviour of the pile near the slope is similar to that of a pile placed in leveled ground. For example, at a deformation of $20 \mathrm{~mm}$ and a target depth of $1.5 \mathrm{~m}$, the value of the p-multiplier is $0.76,0.78,0.97$, and 0.999 for the $0 \mathrm{D}, 2 \mathrm{D}, 4 \mathrm{D}$, and $8 \mathrm{D}$ case respectively. Overall, it was found that the p-multiplier ranges between (0.4-0.8) for the pile at a distance of $0 \mathrm{D},(0.6-0.83)$ for a distance of 2D, (0.8-0.95) for a distance of $4 \mathrm{D}$, and (0.98-1) for a distance of $8 \mathrm{D}$ for various target depths.

\section{Parametric Study}

A parametric study, divided into 2 phases, was performed to study the effect of slope inclinations, distance of the pile from the crest and target depth on the p-y curves, as well as the normalized curves.

\section{1) Parametric Study on Backcalculated P-Y Curves}

To better understand the effect of slope inclinations on the back-calculated p-y curves constructed from numerical analysis, at various target depths and distances of the pile from the crest, a parametric study, shown in(d)

Fig. 10. was conducted.

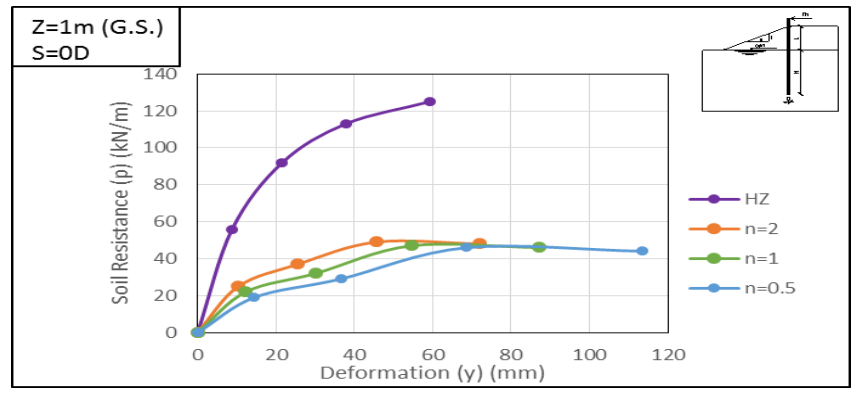

(a) 


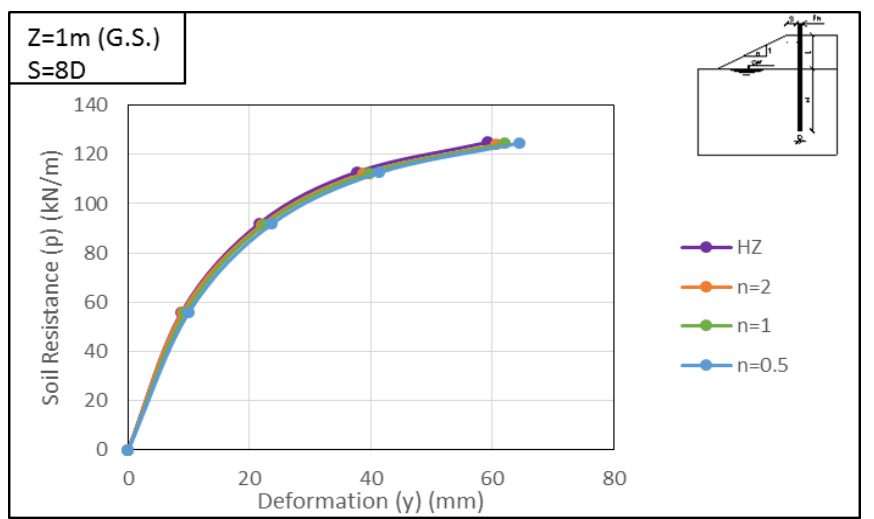

(b)

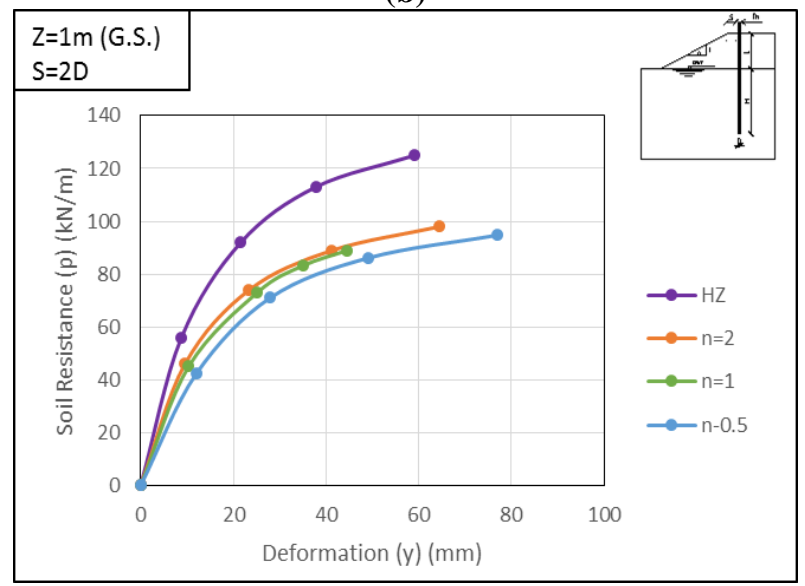

(c)

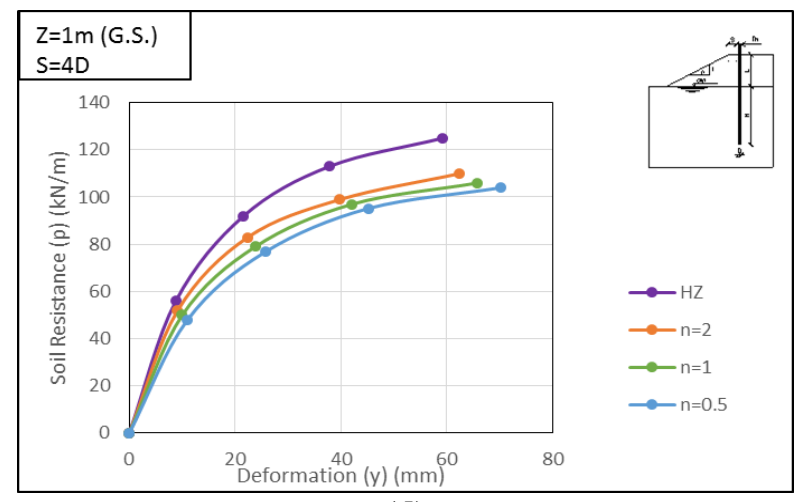

(d)

Fig. 10. Effect of Slope Inclination on Backcalculated p-y curves from Numerical Analysis at Depth $\mathrm{z}=1 \mathrm{~m}$ from

Top of Pile at Distances; a)0D b)2D c)4D d)8D from Crest

The figures above offer a logical graphical representation of the actual behaviour in site conditions. Taking the case of $n=2, Z=1 m$ as an example, at a distance of $0 D$, the value ' $p$ ' corresponding to a lateral deformation at the top of the pile of $40 \mathrm{~mm}$ is $46 \mathrm{kN} / \mathrm{m}$, while for the same deformation, the value ' $p$ ' for the backbone curve is $118 \mathrm{kN} / \mathrm{m}$. Also, at $\mathrm{n}=2, \mathrm{Z}=1 \mathrm{~m}$, at a distance of $4 \mathrm{D}$, the value ' $\mathrm{p}$ ' corresponding to a lateral deformation at the top of the pile of $40 \mathrm{~mm}$ is $100 \mathrm{kN} / \mathrm{m}$ drawing nearer to the backbone curve value. Finally, at a distance of $8 \mathrm{D}$ the value ' $\mathrm{p}$ ' corresponding to a lateral deformation at the top of the pile of $40 \mathrm{~mm}$ is $117.8 \mathrm{kN} / \mathrm{m}$ almost identical to the backbone value, concluding that the effect of slope is negligible at a distance of $8 \mathrm{D}$ from the crest of the slope or greater.

Another apparent deduction from the figures above is, as the slope inclination angle decreases, the p-y curve for the pile near slope approaches the backbone curve. For example, at $\mathrm{Z}=1 \mathrm{~m}, \mathrm{~S}=4 \mathrm{D}$, for a deformation of $20 \mathrm{~mm}$, the soil resistance per unit length, p, equals $76.8,79$, 83, and 92 for $\mathrm{n}=0.5,1,2$ and horizontal ground respectively.

\section{2) Parametric Study on Normalized p-y Curves}

Similar to the parametric study in the previous section, the effect of slope inclinations on the normalized p-y curves was investigated and the findings are shown in Fig. 11. at various distances of the pile from the crest.

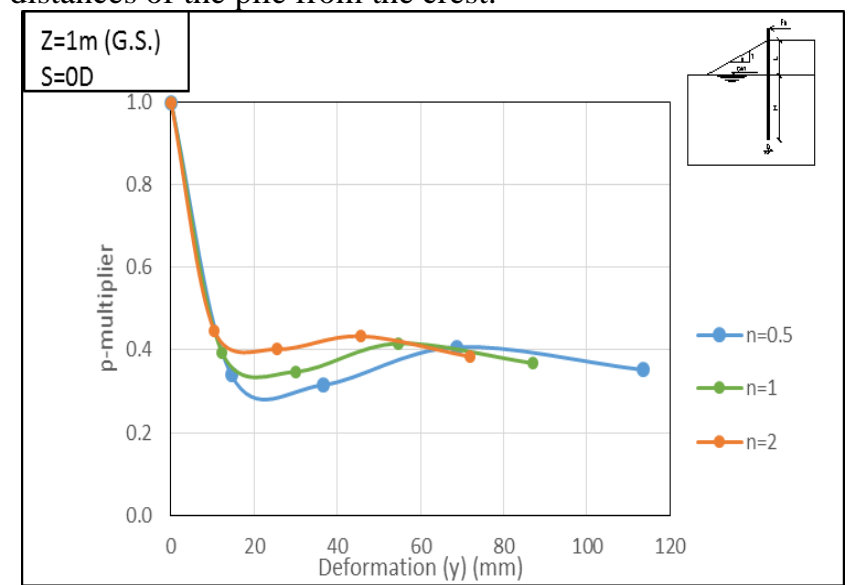

(a)

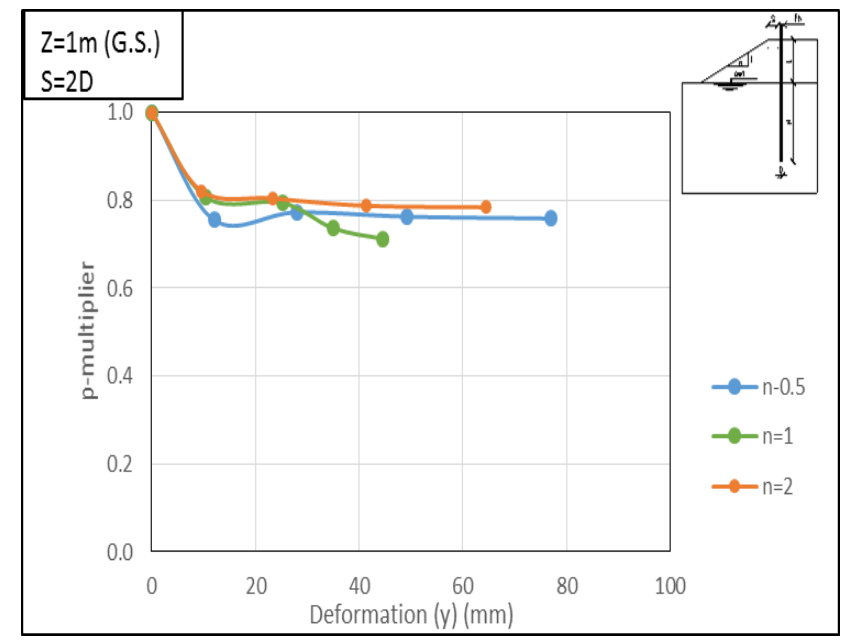

(b)

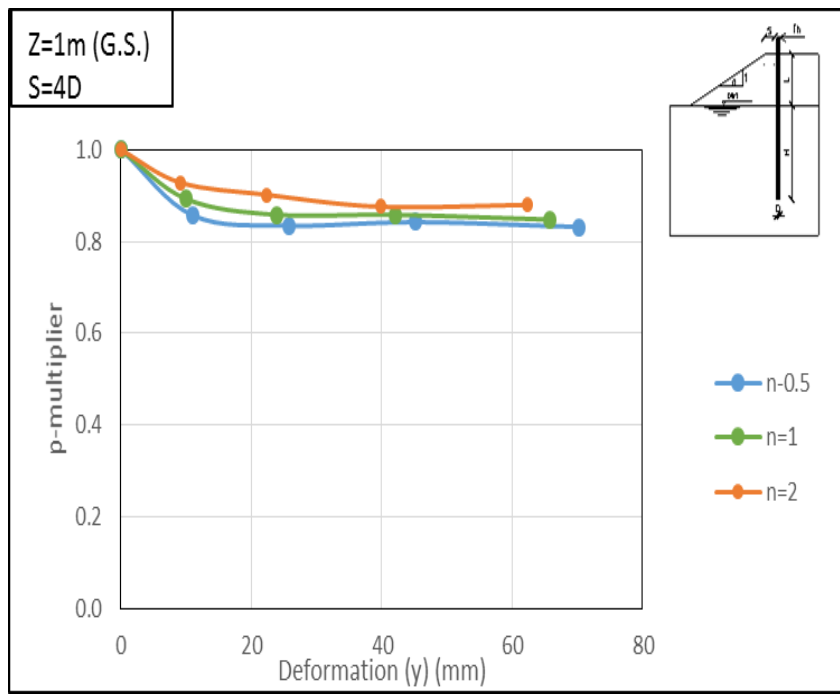

(c) 


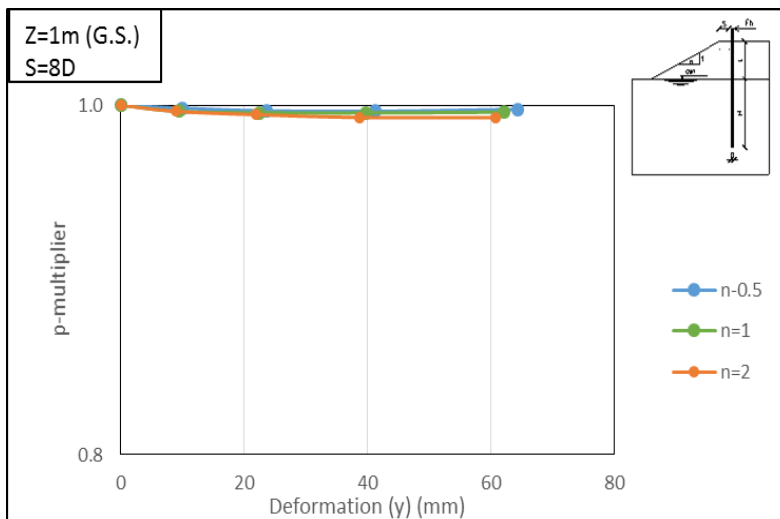

(d)

Fig. 11. Effect of Slope Inclination on Normalized p-y curves from Numerical Analysis at Depth $\mathrm{z}=1 \mathrm{~m}$ from Top of Pile at Distances; a)0D b)2D c)4D d)8D from Crest

It is clear from the graphs that the p-multiplier for the target depth at any distance of the pile from the crest increases as the value " $n$ " increases, where " $n$ " is the horizontal ratio of the slope. These findings are reasonable since, at $\mathrm{n}=0.5$ the slope inclination is very steep, causing a significant loss in passive soil resistance. While $n=2$ provides a relatively gentler inclination closer to a flat terrain. Also, the $p=$ multiplier at a certain target depth increases as the pile is placed at a distance farther from the slope until it tends to 1 when the pile is at a distance of $8 \mathrm{D}$ from the slope. Confirming that the effect of slope vanishes at a distance of $8 \mathrm{D}$ and greater regardless of the value of the slope inclination. The p-multiplier for the studied slope inclinations ranges between (0.3-0.45) for the pile at a distance of $0 \mathrm{D}$, (0.76-0.8) at a distance of $2 \mathrm{D},(0.82-0.93)$ at a distance of $4 \mathrm{D}$, and (0.98-1) at a distance of 8D.

\section{SUMMARY AND CONCLUSIONS}

Based upon the numerical analysis model and construction of p-y curves using the finite difference technique, the following conclusions can be drawn:

- The numerical analysis model can accurately represent the field case study regarding the load vs. deformation curve for working loads. However, as the applied loads approach the ultimate state, the model fails to accurately simulate the site conditions due to the nonlinearity of the steel pile, which wasn't taken into consideration.

- The soil resistance increases with depth measured downward along the pile length.

- Numerical analysis model can be used for back calculating $\mathrm{p}-\mathrm{y}$ curves implementing the finite difference method.

- As the slope inclination angle decreases, the p-y curve for the pile located near the earth slope approaches the backbone curve, case of leveled ground.

- The value of the p-multiplier, at a certain target depth, increases as the pile is placed farther from the crest of the slope until it tends to 1 when the pile is placed at a distance of $8 \mathrm{D}$; i.e., the effect of slope diminishes at a distance of $8 \mathrm{D}$ and the lateral behaviour of the pile near the earth slope is similar to that of a pile placed in leveled ground.

- For various target depths, the p-multiplier ranges between (0.4-0.8) for the pile at a distance of $0 \mathrm{D}$, (0.6-0.83) at a distance of 2D, (0.8-0.95) at a distance of $4 \mathrm{D}$ and $(0.98-1)$ at a distance of $8 \mathrm{D}$.

- The p-multiplier for the studied slope inclinations $(n=0.5,1,2)$ ranges between $(0.3-0.45)$ for the pile at a distance of $0 \mathrm{D},(0.76-0.8)$ at a distance of $2 \mathrm{D}$, (0.82-0.93) at a distance of $4 \mathrm{D}$ and $(0.98-1)$ at a distance of $8 \mathrm{D}$ for a target depth of $1 \mathrm{~m}$.

- The proposed p-multipliers in this study can be implemented into p-y curves software, such as LPILE, to determine the straining actions required for design of a laterally loaded pile near sloping ground.

\section{REFERENCES}

1. H. Poulus, "Behaviour of Laterally Loaded Piles Near a Cut or Slope," Aust. Geomech. J., 1976.

2. L. Reese and H. Matlock, "Non-dimensional solutions for laterally-loaded piles with soil modulus assumed proportional to depth," 1956.

3. L. C. Reese, W. R. Cox, and F. D. Koop, "Field testing and analysis of laterally loaded piles in sand," 1974

4. H. Matlock, "Correlations for design of laterally loaded piles in soft clay," 1970.

5. L. Reese, W. R. Cox, and F. D. Koop, "Field testing and analysis of laterally loaded piles in stiff clay," 1975.

6. Mezazigh and D. Levacher, "Laterally loaded piles in sand: slope effect on p-y reaction curves,” Can. Geotech. J., vol. 35, no. 3, pp. 433-441, 1998.

7. C. Chen and G. Martin, "Effect of embankment slope on lateral response of piles," FLAC Numer. Model. Geomech., pp. 205-213, 2001.

8. K. Chae, K. Ugai, and A. Wakai, "Lateral resistance of short single piles and pile groups located near slopes," Int. J. Geomech., vol. 4, no. 2, pp. 93-104, 2004.

9. A. D. Mirzoyan, "Lateral Resistance of Piles At the Crest," no. December, 2007.

10. K. Georgiadis and M. Georgiadis, "Undrained lateral pile response in sloping ground," J. Geotech. geoenvironmental Eng., vol. 136, no. 11, pp. 1489-1500, 2010.

11. N. Nimityongskul, P. Barker, and S. Ashford, "Effect of soil slope on lateral capacity of piles in cohesive and cohesionless soils," Masters thesis, 2012.

12. R. M. Verhoef, "Laterally Loaded Piles in Sloping Ground," Delft University of Technology, 2015.

13. V. K. Chandaluri and V. A. Sawant, "Effect of Slope Angle on Pile Response,” Indian J. Sci. Technol., vol. 9, no. 48, 2017.

14. D. L. Pradhan, "Development of P-Y Curves for Monopiles in Clay using Finite Element Model Plaxis 3D Foundation,” no. June, 2012.

15. M. Yang, B. Deng, and Y. Wang, "A Simplified Calculation Method for the Near-Slope Laterally Loaded Pile Based on a Passive Wedge Model," Adv. Civ. Eng., vol. 2019, p. 8363252, 2019.

\section{AUTHORS PROFILE}

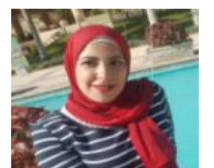

Soha Emad Said is a teaching assistant of geotechnical engineering at the faculty of engineering, Ain Shams University that is one of the top universities in the middle east and Africa, where she also received her bachelor's degree in civil engineering. She has done intensive research regarding the lateral behviour of piles and simulating that behavior in numerical finite element model analysis. This paper is part of her research in her MSc. thesis focusing on development of $\mathrm{p}-\mathrm{y}$ curves from numerical analysis using the finite difference technique.

Contact information: Geotechnical Engineering and Foundations Laboratory, Faculty of Engineering, Ain Shams University, 1 El Sarayat st., El Waili, Postal code 11535, Cairo, Egypt.

Tel: +20-1068027826

E-mail: soha.emad@eng.asu.edu.eg.
Published By:

Blue Eyes Intelligence Engineering \& Sciences Publication 


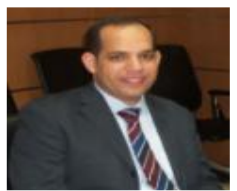

Dr. Ayman Fayed has over 25 years of experience as an educator, researcher and consultant specializing in the areas of deep excavations, ground improvement, shallow and deep foundations, soil-structure interaction and in-situ testing of soils. Dr. Fayed is an Associate Professor of geotechnical engineering at the faculty of engineering, Ain Shams University that is one of the top universities in the middle east and Africa. Through his academic career, Dr. Fayed has authored or coauthored many publications in the geotechnical and foundation engineering field that were published in international journals and conferences. Dr. Fayed, as well, has supervised or co-supervised, several M.Sc. and Ph.D. dissertations in geotechnical engineering. As an engineering consultant working at Dar Al-Hadassah consultants, that is one of the top engineering firms in the world, Dr. Fayed has participated in the design and management of large scale geotechnical projects in different regions of the world especially in the middle east and Africa. Contact information: Geotechnical Engineering and Foundations Laboratory, Faculty of Engineering, Ain Shams University, 1 El Sarayat st., El Waili, Postal code 11535, Cairo, Egypt.

Tel: +20-1006666502

E-mail: ayman.fayed@eng.asu.edu.eg.

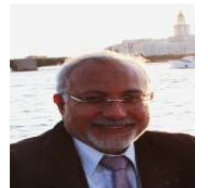

Prof. Yasser El-Mossallamy has been a researcher and consultant for 34 years. His work includes the application of numerical modeling and analyses in geotechnical projects. He has a wide experience by the design and construction of raft and piled raft foundations of high-rise buildings and bridge foundation. He was also involved in many projects dealing with special measures to increase stability of landslides, soil improvement, rock fall hazards and tunneling. Prof. El-Mossallamy has finished his PhD in Germany and has worked by ARCADIS Consult in Germany for about 13 years. Prof. El-Mossallamy joints till now Arcadis in many projects worldwide (e.g. 3rd Istanbul Airport). Prof. Yasser has a wide experience in different countries such as Germany, China, Turkey, Egypt, Saudi Arabia, Kuwait and UAE, Jordanian. Prof. El-Mossallamy has a wide experience with Mega projects dealing with foundation of high-rise buildings, bridges, tunnels, dams, highways, railways, airports and silos.

Prof. El-Mossallamy is also a professor at Ain Shams University, Cairo, Egypt. Prof. El-Mossallamy has more than 100 publications dealing with different geotechnical topics. Contact information: Geotechnical Engineering and Foundations Laboratory, Faculty of Engineering, Ain Shams University, 1 El Sarayat st., El Waili, Postal code 11535, Cairo, Egypt.

Tel: +20-1006666502

E-mail: yasserelmossallamy@gmail.com.

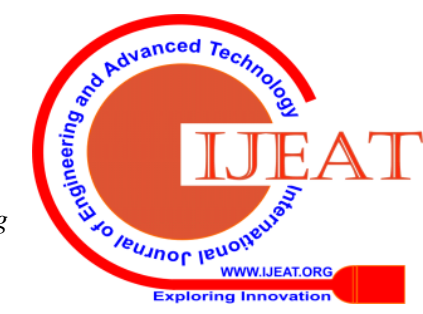

